\title{
Gold Catalyst in PROX: The Role of Dopant and Reaction Exothermicity
}

\author{
Fang WANG
}

\author{
Key Laboratory of materials chemistry in Binzhou City, Department of Chemical Engineering, \\ Binzhou University, Binzhou 256600, Shandong Province, P. R. C
}

wangfangosso@163.com

\begin{abstract}
Keywords: Gold Catalyst, CO Oxidation, Exothermicity.
\end{abstract}
\begin{abstract}
Reaction exothermicity over $\gamma$-alumina supported gold catalysts could be well controlled by addiing appropriate dopant. The addition of adopant $\mathrm{FeOx}$ and $\mathrm{CeO}_{2}$ could transfer active species $\mathrm{Au}^{0}$ to $\mathrm{Au}{ }^{\mathrm{III}}$ resulted in different reaction mechanism of $\mathrm{CO}$ oxidation in the absence and presence of $\mathrm{H}_{2}$.
\end{abstract}

\section{Introduction}

Au supported catalysts have been applied widely on $\mathrm{CO}$ oxidation in the absence and presence of $\mathrm{H}_{2}$ owing to their attractive catalytic properties [1]. Although factors that affect the performance of these catalysts, such as the Au particle size, the support, and the preparation method have been studied extensively, studies focused on investigating reaction exothermicity in the process of $\mathrm{CO}$ oxidation reaction are relative scarce. On the one hand, a hot region can have a deleterious impact on the reactor performance and may deactivate the catalyst. Moreover, it may lead to severe safety problems by either initiating highly exothermic reactions, or by decreasing the material strength of the reactor wall. Base on the fact that $\mathrm{CO}$ and $\mathrm{H}_{2}$ oxidations are highly exothermic reactions and the hydrogen oxidation being favored by higher temperature, an effectively control of temperature is an essential measure to ensure high $\mathrm{CO}_{2}$ selectivity. In general, the appropriate temperature can be obtained by changing the structure of reactors [2]. Several design configurations have been proposed to carry out this process. In spite of multistaged reactors are able to handle this highly exothermic reaction system with acceptable selectivity, they have the disadvantage of requiring complex hardware to control temperatures, using staged air injections along the catalyst bed. In this paper, a novel method, i.e. adding an adopant on the catalyst surface was discovered and reaction exothermicity could be controlled effectively.

Traditionally, the tube furnace temperature measured by thermocouple could be considered as the reaction temperature. Obviously, it is inaccurate because of external and internal heat transfer hysteresis. We modified the temperature measure system, here, thin layer catalyst particle were sandwiched between two inactive quartz sand in tube reactor, the reaction tube was embedded in adiabatic reactor. In this case, the catalyst bed temperature can be obtained by thermocouple and its increase is derived from the exothermic reactions. Although it is difficult to determine the reaction exothermicity absolutely because it is much dependent on the size, we think it is possible to obtain the relative tendency of the reaction exothermicity behavior qualitatively.

The catalytic activities for $\mathrm{CO}$ oxidation in the presence and absence of $\mathrm{H}_{2}$ on the original and MOx $(\mathrm{M}=\mathrm{Fe}$ and $\mathrm{Ce})$ doped $\mathrm{Au} / \mathrm{Al}_{2} \mathrm{O}_{3}$ catalysts were investigated at ambient temperature. Based on their attractive catalytic performances for $\mathrm{CO}$ oxidation in the absence of $\mathrm{H}_{2}$, the surface temperatures over various Au catalysts were studied as shown in Fig.1(left). All catalysts surface temperatures were enhanced significantly by increasing $\mathrm{CO}$ concentration in the reaction stream, owing to reaction exotherm increase. The maximum temperature obtained from $\mathrm{Au} / \mathrm{Al}_{2} \mathrm{O}_{3}$ was $160^{\circ} \mathrm{C}$ when $\mathrm{CO}$ concentration was raised to $20 \%$, whereas the corresponding temperature on the $\mathrm{Fe}_{2} \mathrm{O}_{3}$ and $\mathrm{CeO}_{2}$ doped catalyst was just $55^{\circ} \mathrm{C}$ and $100{ }^{\circ} \mathrm{C}$, respectively. It is interesting to note that the $\mathrm{Au} / \mathrm{Al}_{2} \mathrm{O}_{3}$ catalyst surface temperature could be decreased dramatically by $\mathrm{FeOx}$ addition, especially in higher $\mathrm{CO}$ concentration. The surface temperatures over different $\mathrm{Au}$ catalysts in PROX reaction are also shown in Fig.1(right). Marwaha et.al [3] reported that heat generation and heat removal significantly determine the change of product distribution depending on the contact. In 
order to except effect of contact time, the catalyst surface temperatures were studied in the same space velocity. No detectable temperature changes could be found on the $\mathrm{Au} / \mathrm{Al}_{2} \mathrm{O}_{3}$ catalyst surface because of its low catalytic activity for PROX reaction. However, the surface temperatures on both MOx modified catalysts could be increased in a certain extent by raising $\mathrm{H}_{2}$ concentration in the reaction stream. For the $\mathrm{Au} / \mathrm{Al}_{2} \mathrm{O}_{3}-\mathrm{FeOx}$ catalyst, a maximum temperature of $55^{\circ} \mathrm{C}$ was obtained when $\mathrm{CO}$ and $\mathrm{H}_{2}$ concentration were $2.5 \%$ and $50 \%$, respectively. However, the surface temperature of the $\mathrm{Au} / \mathrm{Al}_{2} \mathrm{O}_{3}-\mathrm{CeO}_{2}$ catalyst could achieve $82^{\circ} \mathrm{C}$, and the high temperature resulted in decrease of the corresponding $\mathrm{CO}_{2}$ selectivity. The surface temperature transformation of $\mathrm{FeOx}$ modified catalyst in the region of $5^{\circ} \mathrm{C}$ when $\mathrm{H}_{2}$ concentrations were increased from $40 \%$ to $55 \%$, while $\mathrm{CO}$ concentrations were decreased from $4 \%$ to $2 \%$. These results proved further that the $\mathrm{Au} / \mathrm{Al}_{2} \mathrm{O}_{3}-\mathrm{FeOx}$ catalyst is an appropriate candidate for $\mathrm{CO}$ oxidation in the absence and presence of $\mathrm{H}_{2}$.
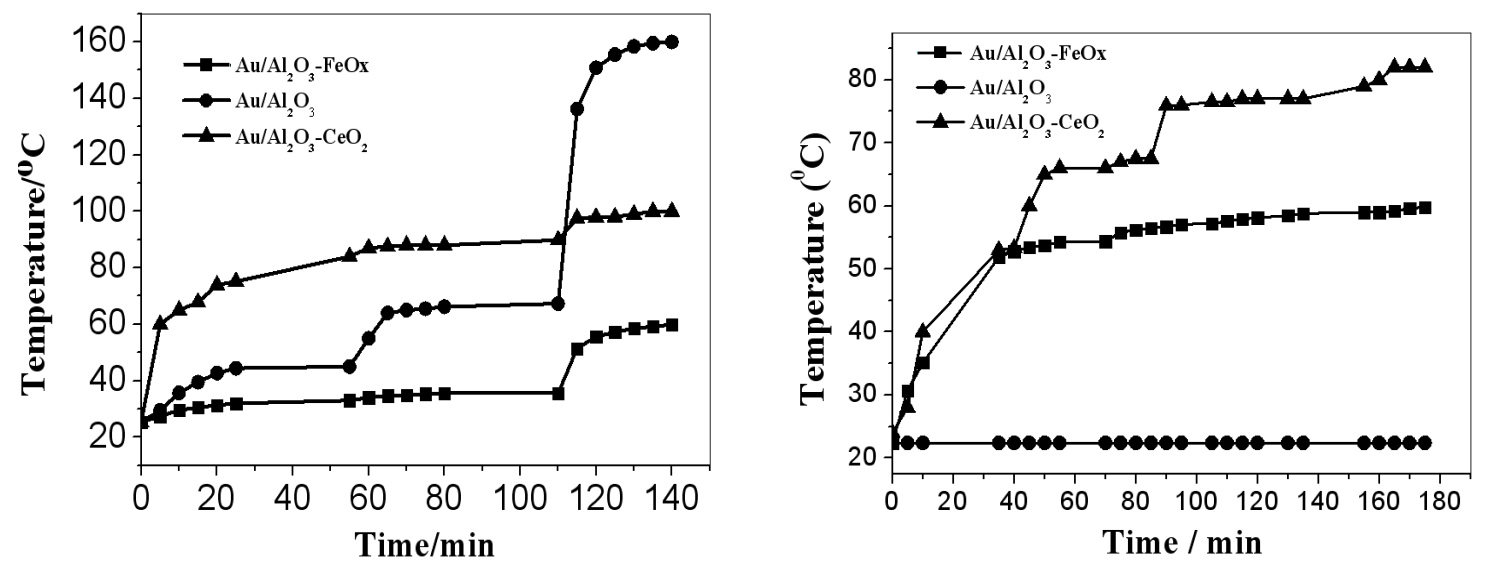

Fig.1 The catalysts surface temperatures for $\mathrm{CO}$ oxidation in the absence and presence of $\mathrm{H}_{2}$

In order to reduce the complexity, only the reactions with significantly rates are considered (CO and $\mathrm{H}_{2}$ oxidation). The catalyst surface temperature in the adiabatic reactor can be calculated according to the equations [4] below:

$$
\begin{aligned}
& \mathrm{T}_{\mathrm{S}}-\mathrm{T}_{\mathrm{g}}=\frac{\kappa_{\mathrm{A}}\left(-\Delta \mathrm{H}_{\mathrm{r}}\right)}{\alpha_{\mathrm{s}} \alpha_{\mathrm{m}}} \\
& \alpha_{\mathrm{s}}=\frac{\mathrm{j}_{\mathrm{H}} \mathrm{GC}_{\mathrm{P}}}{(\operatorname{Pr})^{2 / 3}} \\
& \mathrm{j}_{\mathrm{H}}=\frac{1.10}{(\operatorname{Re})^{0.41}-0.15}
\end{aligned}
$$

Where Tg is reaction mixed-gas temperature, $\alpha_{\mathrm{s}}$ is coefficient of heat transfer, $\alpha_{\mathrm{m}}$ is effective external surface area of catalyst bed per quality unit, and $\Delta \mathrm{Hr}$ is exotherm from $\mathrm{CO}$ and $\mathrm{H}_{2}$ oxidation reactions. $\mathrm{Cp}$ is heat capacity of the reaction mixture under constant pressure, and $\mathrm{j}_{\mathrm{H}}$ is heat transfer factor, while $\mathrm{k}_{\mathrm{A}}$ and $\mathrm{G}$ are reaction rate and mass rate of the reaction mixed-gas. In this case, we consider that the influence of $\alpha_{\mathrm{s}}$ and $\Delta \mathrm{Hr}$ on $\mathrm{Au}$ catalysts surface temperature can be negligeable. It is, however, $\mathrm{Ts}$ rather than $\mathrm{Tg}$ that controls the reaction rate $\mathrm{k}_{\mathrm{A}}$ and also the selectivity of a heterogeneous catalytic process through the Arrhenius equation ( $\mathrm{K}=\mathrm{Aexp}(-\mathrm{Ea} / \mathrm{RTs}))$ [5]. The exponential in Arrhenius' expression for a rate constant has, in fact, not one but two variables, Ea and Ts, which could vary with the imposed experimental conditions and the resulting reaction rates. The traditional interpretation is that the activation energy Ea can be calculated from Ts and the corresponding reaction rates or rate constants. Thus, $\mathrm{k}_{\mathrm{A}}$ and $\alpha_{\mathrm{m}}$ are the factors that can affect the catalyst surface temperature. 
Tab.1 XPS data of different catalysts

\begin{tabular}{|c|c|c|c|}
\hline Catalyst & Center(Au) & $\mathrm{Au}{ }^{I I I} / \mathrm{Au}$ & $\mathrm{Au}(\mathrm{AT}) \%$ \\
\hline $\mathrm{Au} / \mathrm{Al}_{2} \mathrm{O}_{3}$ & 83.62 & 0 & 0.052 \\
\hline $\mathrm{Au} / \mathrm{Al}_{2} \mathrm{O}_{3}-\mathrm{CeO}_{2}$ & 83.76 & 1.8 & 0.054 \\
\hline $\mathrm{Au} / \mathrm{Al}_{2} \mathrm{O}_{3}-\mathrm{Fe}_{2} \mathrm{O}_{3}$ & 83.84 & 3.0 & 0.056 \\
\hline
\end{tabular}

In order to investigate the relationship between various catalysts structure and their surface temperature, a series of characterizations were carried out on various Au catalysts. XPS spectra of $\mathrm{Au} 4 \mathrm{f}$ over the original and $\mathrm{FeOx}$ doped $\mathrm{Au} / \mathrm{Al}_{2} \mathrm{O}_{3}$ catalysts are shown in Table 1. The line shape and width of $\mathrm{Au} 4 \mathrm{f}$ over the original $\mathrm{Au} / \mathrm{Al}_{2} \mathrm{O}_{3}$ catalysts matched well with those of the metallic $\mathrm{Au}$, indicating zerovalence gold was the active center for $\mathrm{CO}$ oxidation at low-temperature. By comparison, the $\mathrm{Au} 4 \mathrm{f}$ feature obtained from $\mathrm{Au} / \mathrm{Al}_{2} \mathrm{O}_{3}-\mathrm{FeOx}$ was quite broad, both zerovalence and cationic gold could be found, which was consistent with the $\mathrm{Au} / \mathrm{Fe}_{2} \mathrm{O}_{3}$ catalyst reported previously [6]. In addition, we can find that the surface atomic concentration is similar,but the $\mathrm{Au}^{\mathrm{III}} / \mathrm{Au}^{0} \mathrm{molar}$ ratio was 1.8 over $\mathrm{Au} / \mathrm{ZnO}-\mathrm{Al}_{2} \mathrm{O}_{3}$, while that increased to 3.0 over $\mathrm{Au} / \mathrm{FeOx}-\mathrm{Al}_{2} \mathrm{O}_{3}$ catalyst. The result indicated that the valent state of gold particles on the catalyst surface could be changed by adopant addition. It is already well proven that both $\mathrm{Au}^{\mathrm{III}}$ and $\mathrm{Au}^{0}$ species are active for $\mathrm{CO}$ oxidation [7]. Once the catalyst is exposed to a $\mathrm{CO} / \mathrm{O}_{2}$ mixture, the $\mathrm{Au}{ }^{\mathrm{III}} / \mathrm{Au}^{0}$ ratio decreases and after a sufficiently long exposure only metallic gold is left. This result proves that the lattice oxygen of cationic gold does participate in the reaction of $\mathrm{CO}$ oxidation. The XPS result from $\mathrm{Au} / \mathrm{FeO}_{\mathrm{X}}-\mathrm{Al}_{2} \mathrm{O}_{3}$ catalyst showed that no $\mathrm{Au}^{\mathrm{III}} / \mathrm{Au}^{0}$ ratio decline could be found. We consider that cationic gold species does not participate in $\mathrm{CO}$ oxidation at low temperature, which maybe play an important role at higher temperature. In other words, the decline in activity caused by the $\mathrm{Au}^{\mathrm{III}} / \mathrm{Au}^{0}$ ratios decrease can be inhibitted by controlling the hot spot temperature.

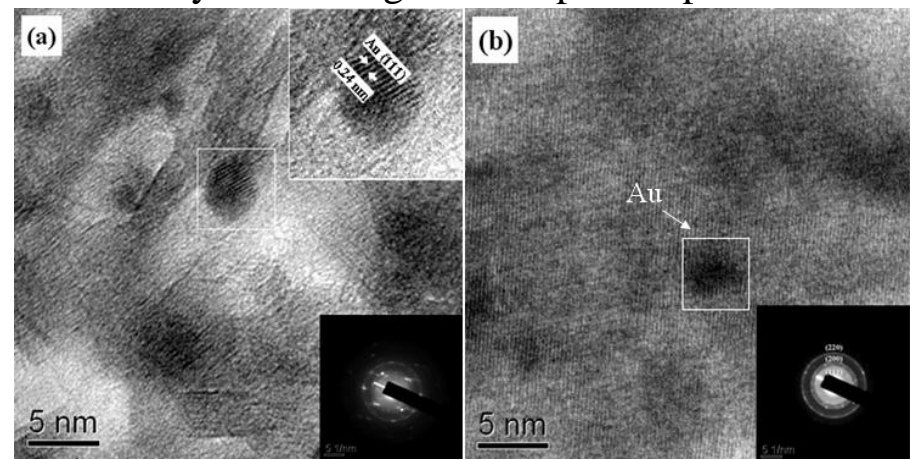

Fig. 2 HRTEM images of (a) $\mathrm{Au} / \mathrm{Al}_{2} \mathrm{O}_{3}$; (b) $\mathrm{Au} / \mathrm{Fe}_{2} \mathrm{O}_{3}-\mathrm{Al}_{2} \mathrm{O}_{3}$

HRTEM images from different supported $\mathrm{Au}$ catalysts are shown in Fig.2. The Au nanoparticles on all catalysts had a uniform size around $5 \mathrm{~nm}$ and were well dispersed and embedded in mesostructured support matrix. The fringes in Fig.2(a) gave a d-spacing of 0.24 $\mathrm{nm}$, corresponding to the (111) atomic planes of gold lattice. This result shows that the catalysts surface temperature difference can not be attributed to the active component particle size, which is distinguished from $\mathrm{NiO} / \mathrm{Al}_{2} \mathrm{O}_{3}$ catalyst reported previous [8]. Both polycrystal and single crystal of gold particles coexisted over $\mathrm{Au} / \mathrm{FeOx}-\mathrm{Al}_{2} \mathrm{O}_{3}$, the degree of crystallinity is much lower than that on the $\mathrm{Au} / \mathrm{Al}_{2} \mathrm{O}_{3}$ catalyst. Furthmore, the Au lattice on $\mathrm{Au} / \mathrm{FeO}_{\mathrm{x}}-\mathrm{Al}_{2} \mathrm{O}_{3}$ prefers to become strongly distorted so as to adopt the lattice dimensions of the mixed- oxide support, which is similar to $\mathrm{Au}$ nanoparticles supported on $\mathrm{TiO}_{2}$ [9]. These results indicated that there was a strong interaction between $\mathrm{Au}$ and $\mathrm{FeO}_{\mathrm{x}}$. DFT calculations have shown that lattice strain may enhance surface reactivity [10]. It has been suggested to explain the unusually high low-temperature $\mathrm{CO}$ oxidation activity of small Au particles.

Based on the foregoing observations and discussions, we can summarize schematically the adsorption of $\mathrm{CO}, \mathrm{O}_{2}$ and/or $\mathrm{H}_{2}$ on three catalysts. The difference of the catalysts surface temeratures might mainly due to various active centers, which can result in different reaction mechanisms. With respect to the $\mathrm{Au} / \mathrm{Al}_{2} \mathrm{O}_{3}$ catalyst, support $\mathrm{Al}_{2} \mathrm{O}_{3}$ usually can be regarded as 
chemical inert for $\mathrm{CO}$ oxidation. Thus, oxygen adsorption and dissociation must be possible on the metallic $\mathrm{Au}$ nanoparticles. No PROX reaction occurs because the active sites are fully covered with $\mathrm{H}_{2}$ or $\mathrm{CO}$ strongly adsorbed on the $\mathrm{Au} / \mathrm{Al}_{2} \mathrm{O}_{3}$ catalyst due to blocked access of $\mathrm{O}_{2}$ to the reaction sites. This strongly indicates that a dissociative adsorption of $\mathrm{O}_{2}$ and the following surface reaction with preadsorbed $\mathrm{CO}$ are essential for PROX reaction, similar to Langmuir-Hinshelwood mechanism. While for the $\mathrm{Au} / \mathrm{Al}_{2} \mathrm{O}_{3}-\mathrm{MO}_{\mathrm{x}}$ catalyst, on the one hand, $\mathrm{CO}$ oxidation reaction can occur at the interface between $\mathrm{Au}$ and the adopant $\mathrm{MO}_{\mathrm{x}}$, just as the $\mathrm{Au} / \mathrm{Fe}_{2} \mathrm{O}_{3}$ catalyst [11]. Moreover, the addition of $\mathrm{MO}_{\mathrm{x}}$ can enhance the oxygen vacancy, which is in favor of the adsorption of $\mathrm{CO}$ and active oxygen species. Therefore, the $\mathrm{Au} / \mathrm{Al}_{2} \mathrm{O}_{3}-\mathrm{MO}_{\mathrm{x}}$ catalyst are very effective for the inhibition of the hot spot formation in $\mathrm{CO}$ oxidation reaction, mainly due to the low oxygen affinity of $\mathrm{Au}$ [12], which resulted from MOx modification. Herein, we think that there maybe a so-called bifounctional mechanism exist over the $\mathrm{Au} / \mathrm{Al}_{2} \mathrm{O}_{3}$ $\mathrm{MO}_{\mathrm{x}}$ catalyst in PROX reaction, just as the Pt-Fe/Mordenite catalysts reported previously [13]. Where $\mathrm{Au}$ sites are available for the adsorption of $\mathrm{CO}$ as well as $\mathrm{H}_{2}$, and the $\mathrm{FeO}_{\mathrm{x}}$ site acts as an $\mathrm{O}_{2}$ dissociative-adsoption site. $\mathrm{CO}$ adsorbed on a $\mathrm{Au}$ site and $\mathrm{O}_{2}$ adsorbed on an $\mathrm{Fe}$ site react immediately at low temperature once both reactants sit on such neighboring site. The mechanism could not only well explain the excellent catalytic performance of the $\mathrm{Au} / \mathrm{Al}_{2} \mathrm{O}_{3}-$ $\mathrm{MO}_{\mathrm{x}}$ catalyst, but also might be responsible for the surface temperature difference between $\mathrm{FeOx}$ and $\mathrm{CeO}_{2}$ modified catalysts.

In summary, the $\mathrm{Au} / \mathrm{MO}_{\mathrm{X}}-\mathrm{Al}_{2} \mathrm{O}_{3}(\mathrm{M}=\mathrm{Ce}$ and $\mathrm{Fe})$ catalysts with high $\mathrm{CO}$ oxidation catalytic performances in the absence and presence of $\mathrm{H}_{2}$ have been synthesized successfully. Reaction exothermicity could be well controlled by adding adopant. The result opens an alternative line in the investigations on better and more selective catalyst materials.

\section{Acknowledgments}

This work has been financially supported by Foundation of Shandong Natural Science Foundation of China (ZR2014BL014), a Project of Shandong Province Higher Educational Science and Technology Program (J14LC54) and Binzhou University (BZXYFB20140806, and 2010Y06.) research Funds.

\section{References}

[1] F. Wang, G.X. Lu. The effect of K addition on Au/activated carbon for CO selective oxidation in hydrogen-rich gas, Catal.Lett. 115(2007) 46-51.

[2] M. Kahlich, H.Gasteiger, R. Beh, Preferential oxidation of $\mathrm{CO}$ over $\mathrm{Pt} / \gamma-\mathrm{AI}_{2} \mathrm{O}_{3}$ and $\mathrm{Au} / \alpha$ $-\mathrm{Fe}_{2} \mathrm{O}_{3}$ : reactor design calculations and experimental results, J. New Mater. Electrochem. Syst. 1(1998)39-46.

[3] B. Marwaha, J. Annamalai, D. Luss, Hot zone formation during carbon monoxide oxidation in a radial flow reactor, Chem. Eng. Sci. 56 (2001) 89-96.

[4] Sh.F. Li, Chemistry and catalytic reaction engineering, 1st ed. Bei Jing, 1986, pp.199-202.

[5] L.J. Zhu, G. Frens,Indications for a Surface Temperature Excess in Heterogeneous Catalysis, J.Phys. Chem. B. 110(2006)18307-18312.

[6] M. Haruta, N. Yamada, T. Kobayash, S. Iijima, Gold catalysts prepared by coprecipitation for low-temperature oxidation of hydrogen and of carbon monoxide, J. Catal. 115(1989) 301-309.

[7] A.M. Visco, F. Neri, G. Neri, et.al. X-ray photoelectron spectroscopy of $\mathrm{Au} / \mathrm{Fe}_{2} \mathrm{O}_{3}$ catalysts, Phys. Chem. Chem. Phys. 11 (1999) 2869-2873. 
[8] B.T. Li, K.J Maruyama, M. Nurunnabi,et.al.Effect of Ni Loading on Catalyst Bed Temperature in Oxidative Steam Reforming of Methane over $\alpha-\mathrm{Al}_{2} \mathrm{O}_{3}$-Supported Ni Catalysts. Ind. Eng. Chem. Res. 44 (2005) 485-494.

[9] J. Graciani, J. Oviedo, J.F. Sanz, V@ $\mathrm{Au}_{12}{ }^{-}$:An Improved Novel Catalyst for CO Oxidation? J Phys Chem B. 110(2006)11600-11603

[10] M. Mavrikakis, B. Hammer, J.K. Nørskov. Effect of Strain on the Reactivity of Metal Surfaces, Phys Rev Lett. 81(1998)2819-2822.

[11]A.K. Tripathy, V.S. Kamble, N.M. Gupta.Gold catalysts prepared by coprecipitation for low-temperature oxidation of hydrogen and of carbon monoxide. J. Catal. 187 (1999)332-342.

[12]T.B. Reed, Free energy formation of binary compounds, MIT press, Cambridge, 1971.

[13] M. Kotobuki, A. Watanabe, H. Uchida, et.al, Reaction mechanism of preferential oxidation of carbon monoxide on Pt, Fe, and Pt-Fe/mordenite catalysts, J. Catal. 236 (2005) 262-269. 